\title{
A study of the correlation between self-confidence and professional achievement of designers
}

\author{
Rain Chen ${ }^{1, a}$, Yu-Tzu Yang ${ }^{2}$, Li-Chou Chen ${ }^{3}$, Chia-Hui Feng ${ }^{2}$ and Gen-Ming Guo ${ }^{4}$ \\ ${ }^{1}$ Department of Visual Communication Design, Southern Taiwan University of Science and Technology, \\ Tainan City 710, Taiwan \\ ${ }^{2}$ Department of Creative Product Design, Southern Taiwan University of Science and Technology, \\ Tainan City 710, Taiwan \\ ${ }^{3}$ Department of Styling and Cosmetology, Tzu Hui Institute of Technology, Pingtung County 926, Taiwan \\ ${ }^{4}$ Department of Information Management, Southern Taiwan University of Science and Technology, \\ Tainan City 710, Taiwan
}

\begin{abstract}
This study mainly investigated which mental state of designers, self-confidence or sense of inferiority, has positive effects on professional design achievement. This study attempted to find if there is correlation between designers' self-confidence or sense of inferiority and their professional achievement. With regard to the tendency of designers' psychological state, the Rosenberg Self-Esteem Scale was used to measure designers' selfconfidence, and statistical computations were made based on gathered data. This study used correlation analysis to find if confidence level of 46 seniors of Design Department is relevant to their professional achievement. The results of the study showed that confidence level of designers has a slight correlation to professional achievement. Factors leading to the study's findings may be the small amount of sample analyzed or may be the reason that the Rosenberg Self-Esteem Scale only detected the current level of self-confidence and could not give a proper feedback on designers' self-confidence during the entire semester. In the future, the results of this study can be considered as a pre-test experiment for a more complete study, and it is expected that results of the study can be for design educators' reference.
\end{abstract}

\section{Introduction}

With the change of time and the trend of globalization, there has been a growing need for designers to seek cross-domain cooperation. Demands for communication among heterogeneous talents of various types are growing rapidly, and a designer's job has changed from an individual's task to a heterogeneous, cross-field collaboration among multiple persons. With the increasing diversification of the design industry, development of an excellent product must rely on the incorporation of various value chains to achieve marketing success.

When product designers are in the process of creative thinking, brainstorming or discussion with one another to refine ideas is often required. It is also necessary for a designer to acquire sufficient knowledge of the relevant industries. Global design trend has also gradually shifted from practical execution to the phase of design thinking. In Asian design community, Taiwanese corporations tend to

\footnotetext{
${ }^{\mathrm{a}}$ Corresponding author : ocean@ stust.edu.tw
} 
work on an OEM or ODM basis so that designers' performance of creativity is often subject to budget. Most designers in small and medium-sized businesses in Taiwan do not get duly paid for their professional contributions. One of the reasons for this could be that there are much emphasis on practical skills, hand-drawing techniques, and computer-aided graphics in the designer training while the development of work attitude and character as a designer has been somewhat ignored.

Colleges and universities seem to have based the professional education of product design solely on skills training. Courses with relation to the cultivation of character and self-identity are generally missing in design education. Besides, humanities and arts education, which are closely related to character development, has not received much attention in Taiwan's technological universities, even though personal traits and interpersonal communication are essential to a successful career for designers.

According to studies by other researchers, optimistic and positive characteristics have great impact on designers' professional achievement. Such personality traits are also applied to industrial designers, but they are the most difficult elements to develop in current education system [1]. Jhang has weighed the capability requirements for industrial design and developed a chart, as shown in Figure 1, in which personality traits rank only second to product planning.

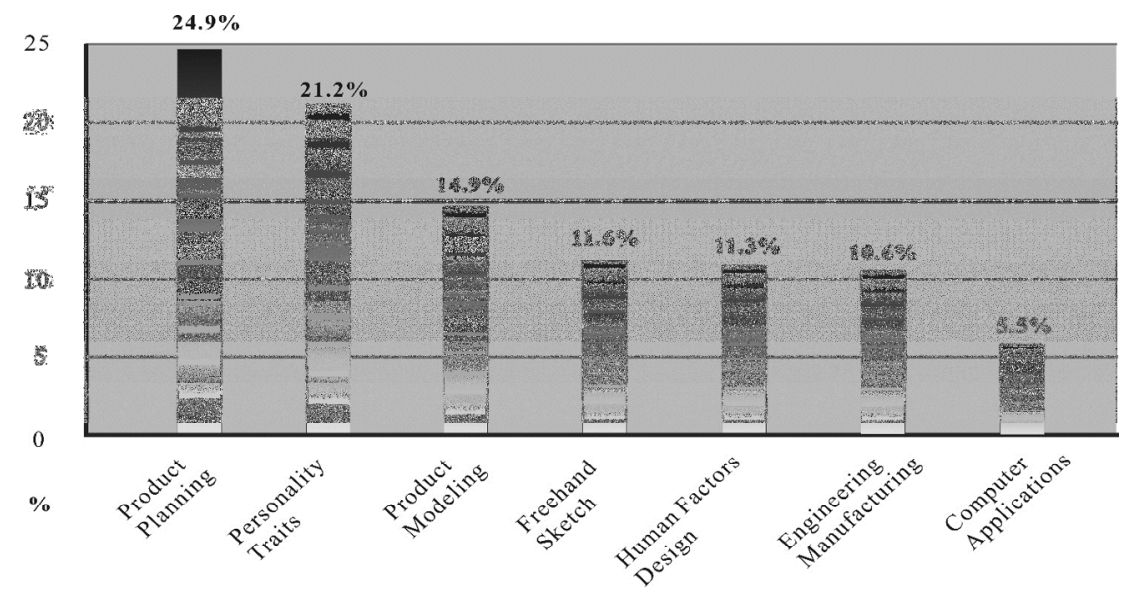

Figure 1. Weights of capability requirements for industrial design.

It is also pointed out in a relevant essay that personality traits are the top requirement for industrial design, followed by the capability of image formation and innovative design. The research results, the essay, and the reality all comply with what scholars have argued: personality traits are the most important quality of designers or people of other professions in modern times. Such traits along with communication skills and expertise and other skills essential for industrial designers are important weapons for competing in the industry [2]. It is stressed in the essay that, in the design profession, personality traits are more important in comparison with design expertise.

Following an argument by Seligman, Alan Carr compared the functions of negative and positive emotions. It is indicated that negative emotions such as fear or anger can serve as a defensive mechanism in evolutionary adaptation while positive emotions help expand the scope of people's concern so that they can sense physical and social environments in a more comprehensive way, accept new ideas, and take new actions, which all lead to a more creative and fruitful outcome [3-4]. According to the study by Tugade \& Fredickson, an individual with positive emotions tends to conduct more diversified thinking and is more likely to be inspired in terms of creativity [5].

\section{Method}

Positive psychology has always been an important concept for psychologists in their study of the connection between people's thinking patterns and their achievements. It has also received much 
attention in organizations and in the field of human resource studies. In assessment dimensions, "personal proficiency" of designers is most valued by industries, with an average score of 4.53, which is above the level of bearing "significant" importance. "Professional abilities" come next with an average score of 4.33.The average score for competence in 2D software and knowledge in ergonomics and in marketing is between 3.9 and 3.0, indicating "fair" to "significant" importance. The rest of the assessment items all above "significant" level. "Background experience" gets an average score of 3.54, with "certification" given the least concern., The reason could be a lack of professional certification system in industrial design in Taiwan, and consequently, industries pay less attention to junior designers' certification [6].

In the book Get Lucky, author Xuan Liu broached studies related to self-efficacy. After studying patients of phobia in the 1960s, Dr. Albert Bandura, one of the most influential social psychologists in the 20th century, published his theory of self-efficacy in the 1970s. According to Dr. Bandura, selfefficacy stands for "self-confidence concerning whether one can cope with a certain situation." Nowadays, self-efficacy is one of the most popular issues in positive psychology, and its effect has been proven by numerous researches, showing significant association particularly with education, workplace performance, self-management, and exercise and fitness [7].

The topic of this research is "the correlation between self-confidence and professional achievement of designers". It discussed whether a strong correlation between designers' selfconfidence and their professional achievement exists. In Change by Design: How Design Thinking Transforms Organizations and Inspires Innovation, Tim Brown suggested that design thinking is an inner exploration of one's true nature [8]. Today, most projects are far too complicated for any individuals, and the go-it-alone style may soon cause a designer to be weeded out. Even in more conventional fields of industrial design and graphic design, teamwork has become normal. However, it takes patience to organize a project team with people from different backgrounds and fields, and it is not easy to have a flair for recognizing people who possess confidence in their professional abilities and are willing to improve themselves. The essay showed which are managers more concerned about: self-confidence or sense of inferiority. Luh indicated that, from corporations' viewpoint, industrial designers should possess proficiency (attitude) and abilities, of which the former encompasses team spirit, quality of work, self-confidence, curiosity, artistic proficiency, patience, and perseverance [9]. In The Design of Everyday Things, Donald A. Norman also suggested that positive thinking is beneficial for creative thinking as it keeps people moving in the face of failure [10].

The aim of the research was to discuss that, in terms of the design profession, which personality trait can provide positive advantages? Self-confidence or sense of inferiority? Due to practical difficulty in defining personality and proficiency and an intention to implement quantified statistics in the research, Rosenberg's scale was used to analyze the level of designers' self-esteem and thereby to measure their self-confidence. The results of the analysis were then cross-matched against their professional achievement.

The focus of this study was on designers' self-confidence and sense of inferiority, which were measured according to the scores they achieved in the survey and the percentage either psychological state made up. According to the research assumption, subjects with higher self-esteem were deemed to be self-confident or super self-confident, subjects with lower self-esteem were deemed to be the ones with stronger sense of inferiority, and subjects with normal self-esteem were deemed to be average. The research attempted to discuss whether designers' self-esteem has an impact on their professional achievement or not.

The research used grades on graduation projects done by 46 seniors of Design Department. Since a graduation project is the ultimate evaluation of a student of Design Department, it is appropriate to use the grades on the projects as a manifestation of professional achievement. Correlation analysis was implemented in the research to cross-match designers' self-esteem (self-confidence and sense of inferiority) against their professional achievement (grades of graduation projects) and probe any correlation in between. It is expected that the outcome of the research can serve as useful information for design educators' reference regarding future curriculum adjustments. 


\section{Result}

Statistical correlation coefficient and correlation analysis were implemented as research instruments, with an attempt to verify the correlation between designers' self-esteem and their professional achievement. Moreover, it was expected to prove that positive correlation exists between self-esteem and professional achievement. Regarding statistics on gender, 18 of the 46 subjects were males $(39.1 \%)$ and 28 were females $(60.9 \%)$, as shown in Table 1 . The reason to choose college seniors as the research subjects was to examine if there is correlation between their grades on graduation projects and the level of their self-esteem.

Table 1. Statistics on subjects' gender.

\begin{tabular}{|c|c|c|c|c|}
\hline & Frequency & Percent & Valid Percent & $\begin{array}{c}\text { Cumulative } \\
\text { Percent }\end{array}$ \\
\hline 1 (Male) & 18 & 39.1 & 39.1 & 39.1 \\
\hline 2 (Female) & 28 & 60.9 & 60.9 & 100.0 \\
\hline Total & 46 & 100.0 & 100.0 & -- \\
\hline
\end{tabular}

The subjects' scores on the Rosenberg Self-Esteem Scale and their professional achievement (grades on graduation projects) were collected, as shown in Table 2. The ranges of self-esteem scores were: (I) 10-15 points, indicating a sense of inferiority; (II) 16-25 points, indicating average selfesteem; (III) 26-35 points, indicating self-confidence; (IV) 36-40 points, indicating super selfconfidence. The descriptive statistics is shown is Figure 2.

Table 2. Subjects' scores on self-confidence and professional achievement.

\begin{tabular}{|c|c|c|c|c|c|c|c|c|c|c|c|c|c|}
\hline subject & Q1 & Q2 & Q3 & Q4 & Q5 & Q6 & Q7 & Q8 & Q9 & Q10 & $\begin{array}{c}\text { Self- } \\
\text { esteem } \\
\text { Score }\end{array}$ & Range & $\begin{array}{c}\text { Grade } \\
\text { on } \\
\text { Grad. } \\
\text { Project }\end{array}$ \\
\hline 1 & 3 & 3 & 1 & 2 & 1 & 3 & 3 & 2 & 1 & 1 & 20 & II & 69 \\
\hline 2 & 4 & 2 & 3 & 2 & 3 & 3 & 3 & 2 & 3 & 3 & 28 & III & 71 \\
\hline 3 & 3 & 3 & 3 & 4 & 3 & 3 & 2 & 2 & 2 & 3 & 28 & III & 78 \\
\hline 4 & 4 & 4 & 2 & 2 & 2 & 2 & 2 & 1 & 1 & 1 & 21 & II & 65 \\
\hline 5 & 3 & 1 & 3 & 2 & 2 & 2 & 1 & 2 & 4 & 4 & 24 & II & 65 \\
\hline 6 & 3 & 3 & 2 & 2 & 2 & 4 & 3 & 2 & 2 & 2 & 25 & II & 66 \\
\hline 7 & 4 & 3 & 4 & 4 & 3 & 4 & 4 & 2 & 4 & 4 & 36 & IV & 67 \\
\hline 8 & 4 & 3 & 3 & 3 & 3 & 3 & 4 & 3 & 4 & 4 & 34 & III & 72 \\
\hline 9 & 3 & 2 & 3 & 3 & 4 & 3 & 3 & 2 & 3 & 3 & 29 & III & 74 \\
\hline 10 & 4 & 3 & 4 & 3 & 3 & 4 & 3 & 1 & 4 & 4 & 33 & III & 74 \\
\hline 11 & 2 & 2 & 3 & 2 & 2 & 2 & 2 & 2 & 2 & 2 & 21 & II & 70 \\
\hline 12 & 3 & 2 & 4 & 2 & 3 & 3 & 3 & 2 & 3 & 3 & 28 & III & 70 \\
\hline 13 & 3 & 3 & 2 & 3 & 2 & 2 & 2 & 2 & 1 & 1 & 21 & II & 67 \\
\hline 14 & 4 & 3 & 4 & 3 & 2 & 4 & 4 & 1 & 3 & 3 & 31 & III & 70 \\
\hline 15 & 3 & 3 & 4 & 3 & 4 & 3 & 3 & 2 & 3 & 3 & 31 & III & 71 \\
\hline 16 & 3 & 3 & 1 & 2 & 2 & 3 & 4 & 2 & 1 & 1 & 22 & II & 74 \\
\hline 17 & 3 & 3 & 4 & 3 & 4 & 3 & 3 & 2 & 3 & 3 & 31 & III & 71 \\
\hline 18 & 4 & 3 & 3 & 3 & 1 & 4 & 4 & 1 & 4 & 4 & 31 & III & 70 \\
\hline 19 & 3 & 3 & 4 & 3 & 3 & 3 & 3 & 2 & 4 & 4 & 32 & III & 71 \\
\hline 20 & 3 & 3 & 3 & 3 & 3 & 2 & 2 & 2 & 2 & 3 & 26 & III & 66 \\
\hline 21 & 3 & 3 & 3 & 2 & 2 & 3 & 3 & 2 & 2 & 2 & 25 & II & 66 \\
\hline 22 & 4 & 3 & 3 & 2 & 3 & 3 & 2 & 2 & 2 & 2 & 26 & III & 78 \\
\hline 23 & 3 & 3 & 4 & 3 & 3 & 3 & 2 & 2 & 2 & 2 & 27 & III & 79 \\
\hline 24 & 3 & 3 & 3 & 3 & 2 & 2 & 3 & 1 & 2 & 1 & 23 & II & 75 \\
\hline 25 & 3 & 3 & 3 & 3 & 3 & 3 & 3 & 3 & 3 & 3 & 30 & III & 71 \\
\hline 26 & 3 & 3 & 3 & 2 & 3 & 2 & 2 & 4 & 2 & 2 & 26 & III & 69 \\
\hline
\end{tabular}




\begin{tabular}{|l|l|l|l|l|l|l|l|l|l|l|l|l|l|}
\hline 27 & 3 & 3 & 3 & 3 & 3 & 3 & 3 & 2 & 3 & 3 & 29 & III & 66 \\
\hline 28 & 3 & 3 & 3 & 3 & 3 & 3 & 2 & 2 & 2 & 3 & 27 & III & 71 \\
\hline 29 & 2 & 3 & 3 & 2 & 2 & 2 & 2 & 1 & 2 & 3 & 22 & II & 69 \\
\hline 30 & 3 & 2 & 3 & 3 & 3 & 2 & 2 & 1 & 4 & 3 & 26 & III & 71 \\
\hline 31 & 3 & 3 & 3 & 3 & 3 & 3 & 2 & 2 & 3 & 4 & 29 & III & 67 \\
\hline 32 & 4 & 3 & 3 & 3 & 3 & 3 & 2 & 2 & 3 & 3 & 29 & III & 70 \\
\hline 33 & 4 & 3 & 4 & 4 & 3 & 3 & 3 & 2 & 2 & 2 & 30 & III & 79 \\
\hline 34 & 4 & 3 & 4 & 3 & 3 & 3 & 4 & 2 & 2 & 2 & 30 & III & 75 \\
\hline 35 & 4 & 3 & 4 & 3 & 4 & 4 & 4 & 2 & 4 & 4 & 36 & IV & 71 \\
\hline 36 & 3 & 3 & 3 & 3 & 3 & 3 & 3 & 2 & 2 & 2 & 27 & III & 71 \\
\hline 37 & 1 & 4 & 4 & 1 & 4 & 4 & 4 & 4 & 4 & 4 & 34 & III & 68 \\
\hline 38 & 4 & 3 & 3 & 3 & 3 & 2 & 2 & 2 & 3 & 3 & 28 & III & 71 \\
\hline 39 & 4 & 4 & 2 & 3 & 2 & 3 & 2 & 1 & 1 & 2 & 24 & II & 65 \\
\hline 40 & 3 & 3 & 3 & 3 & 3 & 3 & 3 & 2 & 3 & 2 & 28 & III & 78 \\
\hline 41 & 2 & 3 & 3 & 2 & 3 & 3 & 3 & 2 & 2 & 3 & 26 & III & 70 \\
\hline 42 & 3 & 3 & 3 & 3 & 2 & 3 & 3 & 2 & 3 & 3 & 28 & III & 66 \\
\hline 43 & 3 & 3 & 3 & 3 & 3 & 3 & 3 & 2 & 3 & 3 & 29 & III & 71 \\
\hline 44 & 3 & 3 & 3 & 3 & 3 & 3 & 3 & 2 & 2 & 2 & 27 & III & 71 \\
\hline 45 & 4 & 3 & 4 & 3 & 2 & 3 & 3 & 2 & 3 & 3 & 30 & III & 75 \\
\hline 46 & 3 & 3 & 3 & 3 & 3 & 3 & 3 & 2 & 3 & 3 & 29 & III & 79 \\
\hline
\end{tabular}

Achievement

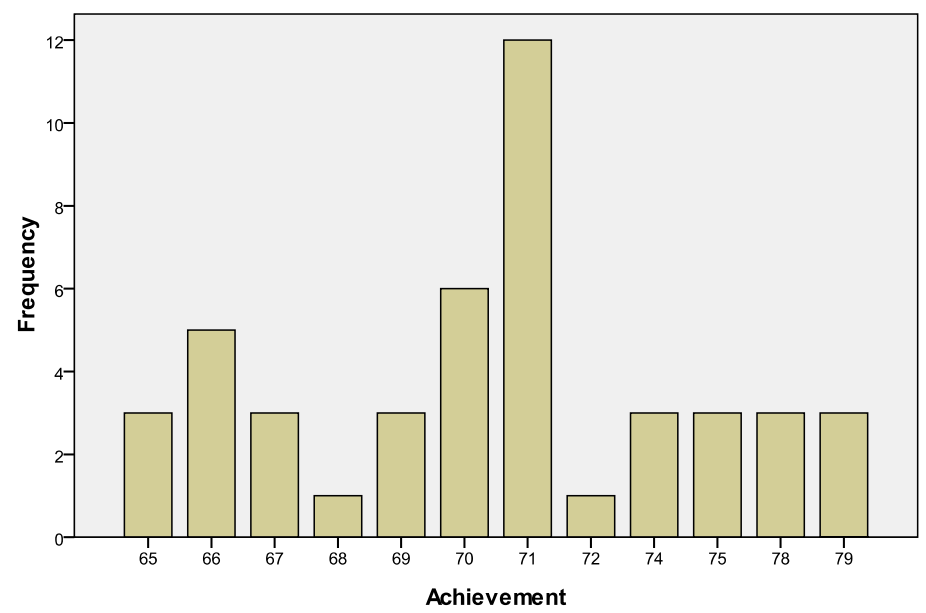

Figure 2. Descriptive statistic on subjects' self-esteem and their professional achievement.

The outcome of the correlation analysis is shown in Table 3 and Figure 3, according to which the Pearson Correlation Coefficient between self-esteem and professional achievement was 0.195. It is therefore revealed that no significant correlation exists between subjects' self-esteem and professional achievement.

Table 3. Correlation analysis between scores on the Rosenberg Scale and professional achievement.

\begin{tabular}{|l|l|c|c|}
\hline Correlation & Items & Rosenberg & Achievement \\
\hline \multirow{5}{*}{ Rosenberg } & Pearson Correlation & 1 & .195 \\
\cline { 2 - 4 } & Sig. (2-tailed) & & .195 \\
\cline { 2 - 4 } & $\begin{array}{l}\text { Sum of Squares and } \\
\text { Cross-products }\end{array}$ & 678.370 & 136.283 \\
\cline { 2 - 4 } & Covariance & 15.075 & 3.029 \\
\hline \multirow{2}{*}{ Achievement } & Pearson Correlation & .195 & 1 \\
\cline { 2 - 4 } & Sig. (2-tailed) & .195 & \\
\hline
\end{tabular}




\begin{tabular}{|l|l|c|c|}
\hline & $\begin{array}{l}\text { Sum of Squares and } \\
\text { Cross-products }\end{array}$ & 136.283 & 722.804 \\
\cline { 2 - 4 } & Covariance & 3.029 & 16.062 \\
\hline
\end{tabular}

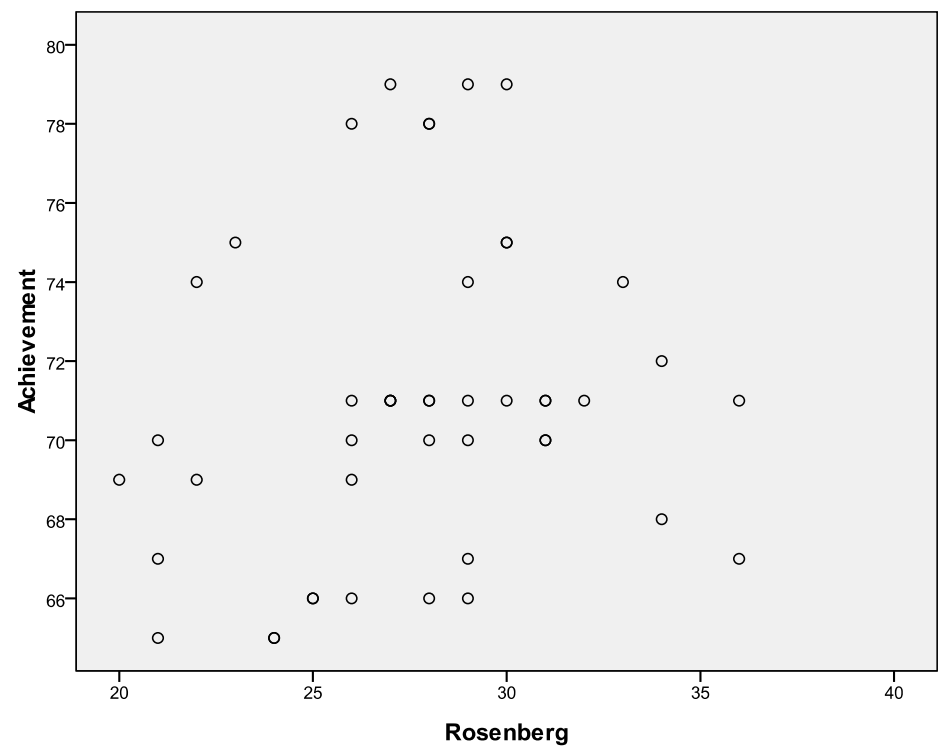

Figure 3. Sample distribution of the Rosenberg Scale and professional achievement.

\section{Discussion and Conclusion}

Over 100 years ago, William James laid the foundations of psychology in America. He acted on his theories and kept reminding himself to be practical and realistic "pursue the cash value of truth in experiential terms." The cash value he sought for his students does not exist in physical currencies or general achievements and glories, but in what he called the ultimate currency. By ultimate currency, he referred to the end of all means, which is happiness. The rate of depression in the U.S. has increased by ten times since the 1960s, and the average age of first onset is 14.5, compared with 21.5 in the 1960s. According to a study conducted by several universities in the U.S., nearly $45 \%$ of college students had learning difficulties due to their suffering from severe depression [11].

Recent studies have revealed that positive emotions work better than negative emotions in terms of effect on the immune system. They can also help improve health. Fredrickson suggested that positive emotions such as happiness, interest, satisfaction, confidence, and love can facilitate actions and broaden people's momentary thought-action repertories, which are of help to building their enduring personal resources and enhancing the sense of happiness [12]. Studies have also shown that individuals with positive mental attitude (greater self-confidence) display more creativity than those with lower self-esteem, which means that positive mental attitude can be predictive of creative performance [13].

However, the outcome of the correlation analysis in the research showed that no significant correlation exists between either high self-esteem or low self-esteem and professional achievement. A possible explanation for such an outcome is that too few samples were available for analysis or that scores of the Rosenberg Self-Esteem Scale represented only designers' self-esteem at the moment instead of their overall confidence throughout the semester. The survey, nevertheless, can be viewed as a pre-test, and more comprehensive studies can be conducted in the future. It is also hoped that the results of such studies can provide useful information for design educators.

Some studies indicated that personality traits of design students are different from those of students of other departments. During training process, designers are asked to show the ability to 
express themselves. It seems that self-confidence has become one of the important factors in designers' success. Though the results of this research showed that there is no significant correlation between self-esteem and professional achievement, researchers may continue to pay attention to this issue in the future and conduct studies of correlation between designers' level of depression and their professional achievement, and which results are believed to be positively beneficial for the improvement of design education.

\section{Acknowledgements}

This work was partially supported by the National Science Council, Taiwan, under the Grant No. MOST 104-2221-E-218-015-MY2.

\section{References}

1. C.J. Jhang, R. Chen, T.Y. Sung, C.C. Lin, Social contacts and achievement of design professionals, Psychology, 5 (8), 478-483 (2015)

2. P.H. Kao, A proposal of pre-service self-assessment scale for industrial designers, Thesis of Ling Tung University (2012)

3. A. Cara, Positive Psychology: The Science of Happiness and Human Strengths, Routledge (2004)

4. M.E.P. Seligman and M. Csikszentmihalyi, Positive psychology: an introduction, American Psychologist, 55 (1), 5-14 (2000)

5. M.M. Tugade and B. L. Fredrickson, Resilient individuals use positive emotions to bounce back from negative emotional experiences, Journal of Personality and Social Psychology, 86 (2), 320333 (2004)

6. Y. Hsu, W.C. Chang, and V. Yang, A study on the recruitment and job performance of newly recruited product designers and their implications in design education, The International Journal of Arts Education, 5 (1), 71-109 (2007)

7. X. Liu, Get Lucky, Bookzone (2014)

8. T. Brown, Change by Design: How Design Thinking Transforms Organizations and Inspires Innovation, HarperBusiness (2009)

9. D.B. Luh, The cultural creation industries plan and the role of industrial design in Taiwan, intercollaboration in design education and research, KAIST International Design Symposium, Seoul, Korea (2004)

10. D.A. Norman, The Design of Everyday Things. Revised and Expanded Edition, Basic Books (2014)

11. B.S. Tal, Happier: Learn the Secrets to Daily Joy and Lasting Fulfillment, McGraw-Hill Education (2007)

12. B.L. Fredrickson, The role of positive emotions in positive psychology, American Psychologist, 56 (3), 218-226 (2001)

13. C.H. Su, The study on the relationship between positive psychology and creativity for the university students, Thesis of University of Taipei (2007) 